\title{
Spontaneous Pregnancy with Severe Ovarian Hyperstimulation Syndrome Undergoing IVF-ET Cycle: A Case Report and Review
}

\author{
Chaonan Peng \\ Shanxi Medical University https://orcid.org/0000-0003-0084-0184 \\ Zhixiao Wang (D1657265753@qq.com) \\ Shanxi Medical University
}

\section{Short communication}

Keywords: In vitro fertilization and embryo transfer, Ovarian hyperstimulation syndrome, Spontaneous pregnancy, Controlled ovarian hyperstimulation, Polycystic ovary syndrome

Posted Date: December 10th, 2020

DOI: https://doi.org/10.21203/rs.3.rs-122462/v1

License: (c) (1) This work is licensed under a Creative Commons Attribution 4.0 International License.

Read Full License 


\section{Abstract}

It is relatively rare that a natural spontaneous with severe ovarian hyperstimulation syndrome (OHSS) occurs undergoing in vitro fertilization and embryo transfer (IVF-ET).Pregnancy can cause OHSS to be delayed, and even lead to pregnancy loss in severe cases. In this case, we introduced the case of a 32year-old female infertile patient with PCOS who underwent IVF-ET cycle and developed severe OHSS before embryo transfer. After volume expansion, symptomatic and supportive treatment and four times of abdominal puncture to extract ascites, the patient's condition is still protracted.However, interestingly, two weeks after giving up treatment, the patient found a spontaneous pregnancy and ended up with biochemical pregnancy. Severe OHSS was also gradually self-healing after biochemical pregnancy.This case emphasizes that pregnancy is one of the high-risk factors of OHSS, which can lead to the delay of the patient's condition with OHSS. Clinicians should be alert to the possibility of spontaneous pregnancy when they take luteal phase ovulation induction treatment undergoing IVF-ET cycle.

\section{Synopsis}

Ovarian hyperstimulation syndrome (ovarian hyperstimulation syndrome, OHSS) mainly occurs in the treatment of assisted reproductive technology(ART), when the ovaries are over-stimulated by ovulation drugs[1-2]. With the increasing maturity of ART in the treatment of infertility, the widespread application of $\mathrm{COH}$ has led to the incidence of OHSS as high as $8.14 \%$ 23.3\%, and increasing year by year[3]. At present, the pathogenesis of OHSS is not completely clear, and its clinical symptoms vary from severity to severity, often accompanied by pleural effusion, ascites, electrolyte disorders, oliguria and liver and kidney damage[4-5]. At present, there is no specific treatment plan for OHSS, but if it can be detected early, given timely expansion, and symptomatic supportive treatment, good therapeutic effects can be achieved. However, most of the OHSS cases described in the above report occurred during $\mathrm{COH}$ treatment cycle, after oocyte retrieval, and occurred at 3 to 5 weeks of pregnancy after fresh embryo transfer[6]. However, it is rarely reported that cases of spontaneous pregnancy combined with severe OHSS occurred during $\mathrm{COH}$ treatment cycly. Here, we describe the case of a 32-year-old infertile woman with PCOS who became pregnant naturally during luteal phase ovulation induction treatment cycle and developed persistent severe OHSS after oocyte retrieval. After discharge from the hospital, the patient was found to be pregnant during the follow-up visit, and the condition was self-healing after biochemical pregnancy. This situation should be highly valued and correctly prevented and treated.

\section{Case Introduction}

A 32-year-old female was admitted to the reproductive center of Taiyuan Central Hospital for "three years of marriage, without contraception and pregnancy for one year after biochemical pregnancy".Combined with clinical symptoms and auxiliary examination, the preliminary diagnosis is primary infertility, PCOS and ovulatory dysfunction. The proposed therapeutic schedule was Letrozole for ovulation induction, and follicular development was monitored by vaginal type B utrasound untill ovulation to guide the coitus behavior on proper time. Letrozole $50 \mathrm{mg}$ was given on the fifth day of menstruation, once a day for 
5 days. Vaginal type $B$ utrasound monitoring on the 10th day of menstruation showed that multiple follicles were developing at the same time, but there was no dominant follicle. At the same time, we checked estradiol (E2) $89.87 \mathrm{ng} / \mathrm{L}$ and progesterone $(P) 0.86 \mathrm{ng} / \mathrm{mL}$. therefore, the treatment plan was changed to IVF-ET and luteal phase stimulate ovulation. On the 10th day of menstruation, $150 \mathrm{IU}$ of gonadotropin $(\mathrm{Gn})$ was given. On the 6th day of $\mathrm{Gn}$ intervention, vaginal type $B$ utrasound was used to monitor the slow growth of follicles, and then the dosage was increased to $225 \mathrm{IU}$. On the 13th day of Gn intervention, vaginal type B utrasound monitoring of follicles revealed 13 follicles with a diameter of $\geq$ $1.6 \mathrm{~cm}$. E2 $1485.24 \mathrm{ng} / \mathrm{L}$, luteinizing hormone (LH) $1.75 \mathrm{mlU} / \mathrm{mL}$, and P $47.5 \mathrm{ng} / \mathrm{mL}$ were checked. Ovulation was triggered by intramuscular injection of $10000 \mathrm{IU}$ of chorionic gonadotropin(hCG) at 21:30 on the same day. Thirty-six hours later, puncture follicles retrieval were performed under the guidance of vaginal type $B$ utrasound. Operation procedure: The patient took the bladder lithotomy position, and routinely disinfected the vulva and vagina. The vaginal type $B$ utrasound showed clear sound images of the bilateral ovaries. 11 follicles were observed and 4 oocytes were obtained. The operation process went smoothly.

4 days after the follicles retrieval, the patient had slight abdominal distension, no nausea, vomiting and other adverse reactions. The vaginal type $B$ utrasound monitoring showed that the right ovary was $13.2 \mathrm{~cm} \times 8.2 \mathrm{~cm}$, and multiple anechoic areas were found in the right ovary, the larger one was $4.5 \mathrm{~cm}$ in diameter, and the left ovary was $13.0 \mathrm{~cm} \times 10.0 \mathrm{~cm}$ in diameter. The larger one was $5.0 \mathrm{~cm}$, and the irregular liquid dark area was about $7.3 \mathrm{~cm}$ in abdominal cavity and $13.7 \mathrm{~cm}$ in pelvic cavity.Considering the patient's medical history, physical signs and auxiliary examination, the patient was considered as moderate OHSS. Therefore, fresh embryo transfer was cancelled and all embryos were frozen. It was recommended that the patient be hospitalized, but the patient refused to be hospitalized.

Eight days after the follicles retrieval, the patient complained of obvious abdominal distension, accompanied by nausea, no vomiting, no sense of suppression in the chest and other s ymptoms, and the abdominal percussion was suspected to be positive. Reexamination of vaginal type $B$ utrasound showed that the right ovary was $17.5 \mathrm{~cm} \times 7.8 \mathrm{~cm}$, and there were multiple anechoic lesions in the right ovary. The diameter of the larger ovary was $4.3 \times 2.7 \mathrm{~cm}$, and the left ovary was $16.3 \mathrm{~cm} \times 9.4 \mathrm{~cm}$. The diameter of the larger ovary was $3.4 \times 4.7 \mathrm{~cm}$. The irregular liquid dark area in the pelvic cavity was about $5.6 \mathrm{~cm}$, and the liver kidney space was deep about $8.8 \mathrm{~cm}$. Combined with symptoms, signs and auxiliary examination, the diagnosis was severe OHSS.Combined with the patient's symptoms, signs and auxiliary examinations, it was diagnosed as severe OHSS.Considering that the patient's condition was serious, he was admitted to the hospital and received symptomatic treatment such as hydroxyethyl starch 13000.4 sodium chloride injection and albumin volume expansion. After admission, the relevant examination was improved. After the patient signed the informed consent form, transvaginal posterior fornix aspiration was performed under sterile conditions. After 13 days of volume expansion, symptomatic supportive treatment and four times of abdominal puncture and drainage treatment, the condition continued to recur. At this time, the patient refused to continue treatment and asked to be discharged. The relevant biochemical indexes and vaginal type $B$ utrasound examination results of the patients during the treatment are shown in Fig. 1, Table1 and Table2.

Page 3/11 
Table 1

biochemical indexes

\begin{tabular}{|c|c|c|c|c|c|}
\hline $\begin{array}{l}\text { Biochemical indexes } \\
\text { Time }\end{array}$ & $\begin{array}{l}\text { 8th day } \\
\text { after } \\
\text { oocyte } \\
\text { retrieval }\end{array}$ & $\begin{array}{l}\text { 11th day } \\
\text { after } \\
\text { oocyte } \\
\text { retrieval }\end{array}$ & $\begin{array}{l}\text { 13th day } \\
\text { after } \\
\text { oocyte } \\
\text { retrieval }\end{array}$ & $\begin{array}{l}\text { 16th day } \\
\text { after } \\
\text { oocyte } \\
\text { retrieval }\end{array}$ & $\begin{array}{l}\text { 20th day } \\
\text { after } \\
\text { oocyte } \\
\text { retrieval }\end{array}$ \\
\hline TP(normal, 65-85 g/L) & 39 & 39 & 37.5 & 39.9 & 42.2 \\
\hline ALB(normal,40-55 g/L) & 24.2 & 24 & 23.7 & 23.8 & 26.8 \\
\hline GLB(normal,20-40 g/L) & 14.8 & 16 & 13.8 & 16.1 & 15.4 \\
\hline FIB(normal, 2-4 g/L) & 5.81 & 5.11 & 5.56 & 5.56 & 5.33 \\
\hline $\begin{array}{l}\text { D- } \mathrm{D}(\text { normal, } \\
0-0.55 \mathrm{mg} / \mathrm{mL})\end{array}$ & 5.5 & 5.2 & 5 & 3.8 & 3.7 \\
\hline WBC(normal,3.5-9.5109/L) & 15.92 & 14.61 & 12.72 & 12.4 & 11.1 \\
\hline RBC(normal,4.3-5.810 $12 / L)$ & 4.65 & 4.28 & 4.29 & 4.09 & 3.43 \\
\hline HGB(normal,130-175 g/L) & 143 & 133 & 127 & 127 & 102 \\
\hline PLT(normal,125-35010/L) & 592 & 606 & 647 & 663 & 642 \\
\hline $\begin{array}{l}\text { Volume of ascites } \\
\text { extracted } \\
(\mathrm{ml})\end{array}$ & 2000 & 3300 & 3380 & - & 3595 \\
\hline 24-hour intake(ml) & 2452 & 3380 & 2430 & 3504 & 3650 \\
\hline 24-hour output(ml) & 3720 & 2090 & 2170 & 2890 & 3290 \\
\hline
\end{tabular}

Table 2

the results of vaginal type $B$ utrasound monitoring

\begin{tabular}{|llllll|}
\hline $\begin{array}{l}\text { Vaginal } \\
\text { type B utrasound } \\
\text { Time }\end{array}$ & $\begin{array}{l}\text { 3th day of } \\
\text { menstruation }\end{array}$ & $\begin{array}{l}\text { 4th day after } \\
\text { oocyte } \\
\text { retrieval }\end{array}$ & $\begin{array}{l}\text { 8th day after } \\
\text { oocyte } \\
\text { retrieval }\end{array}$ & $\begin{array}{l}\text { 11th day } \\
\text { after oocyte } \\
\text { retrieval }\end{array}$ & $\begin{array}{l}\text { 13th day } \\
\text { after oocyte } \\
\text { retrieval }\end{array}$ \\
\hline Left ovary $(\mathrm{cm})$ & $2.6 \times 1.5$ & $13.0 \times 10.0$ & $16.3 \times 9.4$ & $13.0 \times 10.0$ & $12.0 \times 7.8$ \\
\hline Right ovary(cm) & $2.9 \times 1.3$ & $13.2 \times 8.2$ & $17.5 \times 7.8$ & $15.0 \times 11.0$ & $11.7 \times 6.2$ \\
\hline Ascites(cm) & - & 7.3 & 8.8 & 8.6 & 9.5 \\
\hline $\begin{array}{l}\text { Pelvic } \\
\text { effusion(cm) }\end{array}$ & 2.6 & 13.7 & 5.6 & 16.8 & 11.8 \\
\hline
\end{tabular}


After discharge, the patient was asked to review regularly. 31 days after oocyte retrieval, the patient's menstruation was delayed for 2 weeks. The urine pregnancy test was positive, and the serum hCG was $527 \mathrm{mlU} / \mathrm{ml} ; 32$ days after oocyte retrieval, the serum HCG was reexamined at $500 \mathrm{mlU} / \mathrm{ml}$; The serum HCG was $404 \mathrm{mlU} / \mathrm{ml}$ at 35 days after oocyte retrieval; Blood HCG was $267 \mathrm{mlU} / \mathrm{ml}$ at 39 days after oocyte retrieval, considering biochemical pregnancy, OHSS gradually healed.

\section{Discussion}

The overall incidence rate of OHSS was 3.1\% 8.0\% in IVF-ET cycle, and the incidence rate of high-risk patients could be as high as 20\%[7]. According to the World Health Organization(WHO), the incidence of moderate OHSS is $3 \sim 6 \%$, and the incidence of severe OHSS is $0.1 \sim 2 \%[8]$.

The pathogenesis of OHSS is not fully understood, which may be related to the production of various vasoactive substances in the ovaries stimulated by HCG[9-10]. The increase of hCG level in OHSS patients triggers the mutation of FSH receptor, which leads to the increase of corresponding downstream hormones[11]. In addition, hCG is highly sensitive to mutant FSH receptor (FSHR) and glycoprotein hormones with the same subunits are over secreted[12]. However, pregnancy patients themselves also produce more endogenous HCG, which may also be another possible mechanism of OHSS. Recent studies have also shown that all FSHR gene activation mutations are associated with OHSS[13-14].

The main pathological changes of OHSS were multiple follicles and multiple corpus luteum cysts with interstitial edema, which caused ovarian enlargement and abnormal volume[15]. In addition, increased capillary permeability causes fluid to flow into the extravascular cavity, leading to pleural effusion, ascites, pericardial effusion, and even systemic edema. These changes can lead to hypovolemia and the increase of blood drug concentration, which can easily lead to the formation of intravascular thrombosis, renal perfusion insufficiency, and then oliguria and electrolyte disorder[16-17].

The key to prevent OHSS is early identification of high-risk factors, including youth, low body mass index, polycystic ovary syndrome, hypothyroidism, rapid increase of serum E2 levels and previous history of OHSS[18-20]. We should pay attention to the clinical intervention before the treatment of $\mathrm{COH}$ cycle in high-risk groups. During ovulation induction, we should closely monitor blood E2 and B-ultrasound, monitor the size and quantity of follicles. The stimulation program and the dosage of Gn should be adjusted in time to prevent the occurrence of OHSS. Mild OHSS is mostly self-healing. The main purpose of moderate and severe OHSS treatment is capacity expansion and symptomatic and supportive treatment. Early and timely give human serum albumin, low molecular dextran andother intravenous drip to correct blood volume and improve microcirculation[21]. For patients with a large amount of hydrothorax and ascites with chest tightness and abdominal distension pain, it is the quickest and most effective treatment method to improve symptoms. For severe OHSS with more follicles, puncture and aspiration of follicles can achieve good results.

In this case, the risk factors of OHSS included age $<35$ years old, polycystic ovary syndrome, hCG triggering ovulation and pregnancy. Age $<35$ years old is an independent risk factor for OHSS. There are 
more antral follicles in the ovaries of young patients, and the number of follicles collected during $\mathrm{COH}$ cycle is also increased. In addition, there are a large number of $\mathrm{Gn}$ receptors in the ovaries of young patients, and they are prone to overreaction to Gn. PCOS is an ovulation disorder and endocrine disease, which affects about $26 \%$ of women of childbearing age[22]. It significantly increases the risk of OHSS during $\mathrm{COH}$ cycle[23]. The gonadotropin required for follicular development is quite different during $\mathrm{COH}$ cycle, and the follicular development is difficult to control.HCG is widely used in ART cycles for $\mathrm{COH}$ cycle and luteal support. Exogenous hCG can increase the content of the internal hCG, activate renin angiotensin system, and enhance the activities of renin, angiotensin and their invertase, thus producing angiotensin II, the ultimate active substance, resulting in the increase of vascular permeability and the occurrence of OHSS.

In this case, the patient developed moderate OHSS 4 days after oocyte retrieval, and was not hospitalized in time. 8 days after oocyte retrieval, the patient developed into severe OHSS and was hospitalized. After 13 days of volume expansion, supportive symptomatic treatment and four times of peritoneal puncture fluid extraction treatment, the patient's condition was still delayed. Finally, the patient was discharged because she refused to continue treatment. Two weeks after discharge, urine HCG was tested positive and blood HCG gradually decreased, and biochemical pregnancy was considered. The patient did not undergo fresh embryo transplantation due to the consideration of moderate OHSS 4 days after oocyte retrieval. Then, when was the embryo implanted?

After make a detailed inquiry of the patient's medical history, we learned that the patient had no history of coitus during the luteal phase ovulation induction period, but had a history of coitus during letrozole ovulation induction period. Therefore, it was inferred that the patient had ovulation during letrozole ovulation induction period, and normal fertilization and implantation occurred. It is considered that the placenta trophoblast secretes a large amount of endogenous hCG due to pregnancy, which increases the risk of severe OHSS and prolongs the course of disease. Other studies have found that hCG plays a key role in promoting the release of VEGF, which can increase the activity of VEGF[24], thus aggravating the patient's condition.

\section{Conclusion}

Age $<35$ years old, PCOS, hCG triggered ovulation and pregnancy were the high risk factors of OHSS during $\mathrm{COH}$ cycle. Before the treatment of $\mathrm{COH}$, the patients should be evaluated comprehensively and individualized. At the same time, attention should be paid to early identification of high-risk factors of OHSS. It is worth noting that pregnancy is not only a high-risk factor of OHSS, but also can aggravate the progress of OHSS, leading to repeated and prolonged disease. Some scholars believe that the outcome of pregnancy after severe OHSS is similar to that of pregnancy undergoing IVF cycle, so special care is not needed[25]. However, it has been reported that the intelligence of offspring of OHSS patients is decreased, and prenatal estradiol exposure may be related to its pathogenesis[26]. In conclusion, more attention should be paid to monitoring the occurrence of pregnancy during $\mathrm{COH}$ cycle, especially for those who adopt the luteal ovulation induction program, those patients with OHSS who are not cured after 
hospitalization and active expansion and symptomatic supportive treatment should be alert to the possibility of pregnancy, and those with severe symptoms should consider timely termination of pregnancy.

\section{Abbreviations}

OHSS: ovarian hyperstimulation syndrome;

PCOS: polycystic ovary syndrome;

IVF-ET: in vitro fertilization and embryo transfer;

$\mathrm{COH}$ : controlled ovarian hyperstimulation;

ART:assisted reproductive technology;

hCG: chorionic gonadotropin;

VEGF: vascular endothelial growth factor;

E2:estradiol ;

P: progesterone;

LH:luteinizing hormone;

Gn:gonadotropin

Declarations

\section{Acknowledgments}

None.

\section{Funding}

None.

\section{Author information}

\section{Affiliations}

Taiyuan Central Hospital of Shanxi Medical University, Taiyuan, China 


\section{Contributions}

Study design: Peng CN and Wang ZX. Study implementation: Peng CN. Data collection: Peng CN and Wang ZX. Drafting of the manuscript: Peng CN. Approval of final version of the manuscript: Wang ZX. All authors read and approved the final manuscript.

\section{Corresponding author}

Correspondence to Zhixiao Wang.

\section{Ethics declarations}

\section{Ethics approval and consent to participate}

All authors have confirmed that this work complies with the International Committee of Medical Journal Editors (ICMJE) and the Declaration of Helsinki.

\section{Consent for publication}

Written informed consents for this publication were previously obtained from the patients.

\section{Competing interests}

The authors declare that they have no competing interests.

\section{References}

1. Caretto A, Lanzi R, Piani C, et al. Ovarian hyperstimulation syndrome due to follicle-stimulating hormone-secreting pituitary adenomas. Pituitary. 2017;20:553-60.

2. Karimbil B, Maydanovych S, Hingorani J, et al. Ovarian hyperstimulation syndrome (OHSS) in a spontaneous pregnancy with persistent maternal tachycardia, acute renal failure, multiple VTEs (venous thromboembolism) and fetal mirror syndrome: diagnosis and management dilemma. BJOG. 2019;126:23-3.

3. Corbett S, Shmorgun D, Claman P. Prévention du syndrome d'hyperstimulation ovarienne. J Obstet Gynaecol Canada. 2014;36(11):1034-6. 
4. Rastin Z, Ghomian N, Khadem-Rezaiyan M. Severe Ovarian Hyperstimulation Syndrome in A Spontaneous Pregnancy with Normal Singleton Fetus: A Case Report. Iran J Nurs Midwifery Res. 2019;24:310-2.

5. Nakatsuka M, Miyamoto $M$, Soyama $\mathrm{H}$, et al. A case of spontaneous ovarian hyperstimulation syndrome after vaginal delivery. J Obstet Gynaecol. 2019;39:1022-4.

6. Navot D, Bergh PA, Laufer N. Ovarian hyperstimulation syndrome in novel reproductive technologies: prevention and treatment. Fertil Steril. 2019;112:E209-21.

7. Nastri CO, Teixeira DM, Moroni RM, et al. Ovarian hyperstimulation syndrome: pathophysiology, staging, prediction and prevention. Ultrasound Obstet Gynecol. 2015;45(4):377-93.

8. Binder H, Dittrich R, Einhaus F, et al. Update on ovarian hyperstimulation syndrome: Part 1-Incidence and pathogenesis. Int J Fertil Womens Med. 2007;52(1):11-26.

9. Di Carlo C, Savoia F, Ferrara C, et al. Case report: a most peculiar family with spontaneous, recurrent ovarian hyperstimulation syndrome. Gynecol Endocrinol. 2012;28:649-51.

10. Di Carlo C, Bruno P, Cirillo D, et al. Increased concentrations of renin, aldosterone and Ca125 in a case of spontaneous, recurrent, familial, severe ovarian hyperstimulation syndrome. Hum Reprod. 1997;12:2115-7.

11. Lazzaretti C, Riccetti L, Sperduti S, et al. Inferring biallelism of two FSH receptor mutations associated with spontaneous ovarian hyperstimulation syndrome by evaluating FSH, LH and HCG cross-activity. Reprod Biomed Online. 2019;38:816-24.

12. Evbuomwan I. The role of osmoregulation in the pathophysiology and management of Severe Ovarian Hyperstimulation Syndrome. Hum Fertil (Camb). 2013;16:162-7.

13. Di Carlo C, Savoia F, Fabozzi A, et al. A case of ovarian torsion in a patient carrier of a FSH receptor gene mutation previously affected by spontaneous ovarian hyperstimulation syndrome. Gynecol Endocrinol. 2015;31:105-8.

14. Hugon-Rodin J, Sonigo C, Gompel A, et al. First mutation in the FSHR cytoplasmic tail identified in a non-pregnant woman with spontaneous ovarian hyperstimulation syndrome. BMC Med Genet. 2017;18:44.

15. Sonntag B, Keck C. Ovarian hyperstimulation syndrome-prevention strategies and treatment options. Gynakologe. 2019;52:654-8.

16. Darii N, Pavlovic M, Doroftei B, et al. Unsuspected adverse effect of albumin in severe ovarian hyperstimulation syndrome: a case report. JBRA Assist Reprod. 2019;23:430-3.

17. Selter J, Wen T, Palmerola KL, et al. Life-threatening complications among women with severe ovarian hyperstimulation syndrome. Am J Obstet Gynecol. 2019;220:575.e1-11.

18. Timmons D, Montrief T, Koyfman A, et al. Ovarian hyperstimulation syndrome: A review for emergency clinicians. Am J Emerg Med. 2019;37:1577-84.

19. Li XL, Du DF, Li MF. Ovarian hyperstimulation syndrome: a clinical retrospective study on 565 inpatients. Gynecol Endocrinol 2019;1-5. 
20. Thakre N, Homburg R. A review of IVF in PCOS patients at risk of ovarian hyperstimulation syndrome. Expert Rev Endocrinol Metab. 2019;14:315-9.

21. Lee D, Kim SJ, Hong YH, et al. Gonadotropin releasing hormone an-tagonist administration for treatment of early type severe ovarian hyperstimulation syndrome: a case series. Obs Gynecol Sci. 2017;60(5):449-54.

22. Lauritsen MP, Bentzen JG, Pinborg A, et al. The prevalence of polycystic overy syndrome in a normal population according to the Rotterdam criteria versus revised criteria including anti-Mullerian hormone. Hum Reprod. 2014;29(4):791-801.

23. Wu L, Sun Y, Wan J, et al. A proteomic analysis identifies candidate early biomarkers to predict ovarian hyperstimulation syndrome in polycystic overian syndrome patients. Mol Med Rep. 2017;16(1):272-80.

24. Meldrum DR. Preventing severe OHSS has many different facets. Fertil Steril. 2012;97(3):536-8.

25. Xu GF, Zhou CL, Xiong YM, et al. Reduced intellectual ability in offspring of ovarian hyperstimulation syndrome: a cohort study. EBioMedicine. 2017;20:263-7.

26. Choux C, Barberet J, Ginod P, et al. Severe ovarian hyperstimulation syndrome modifies early maternal serum beta-human chorionic gonadotropin kinetics, but obstetrical and neonatal outcomes are not impacted. Fertil Steril. 2017;108(4):650-8.

\section{Figures}




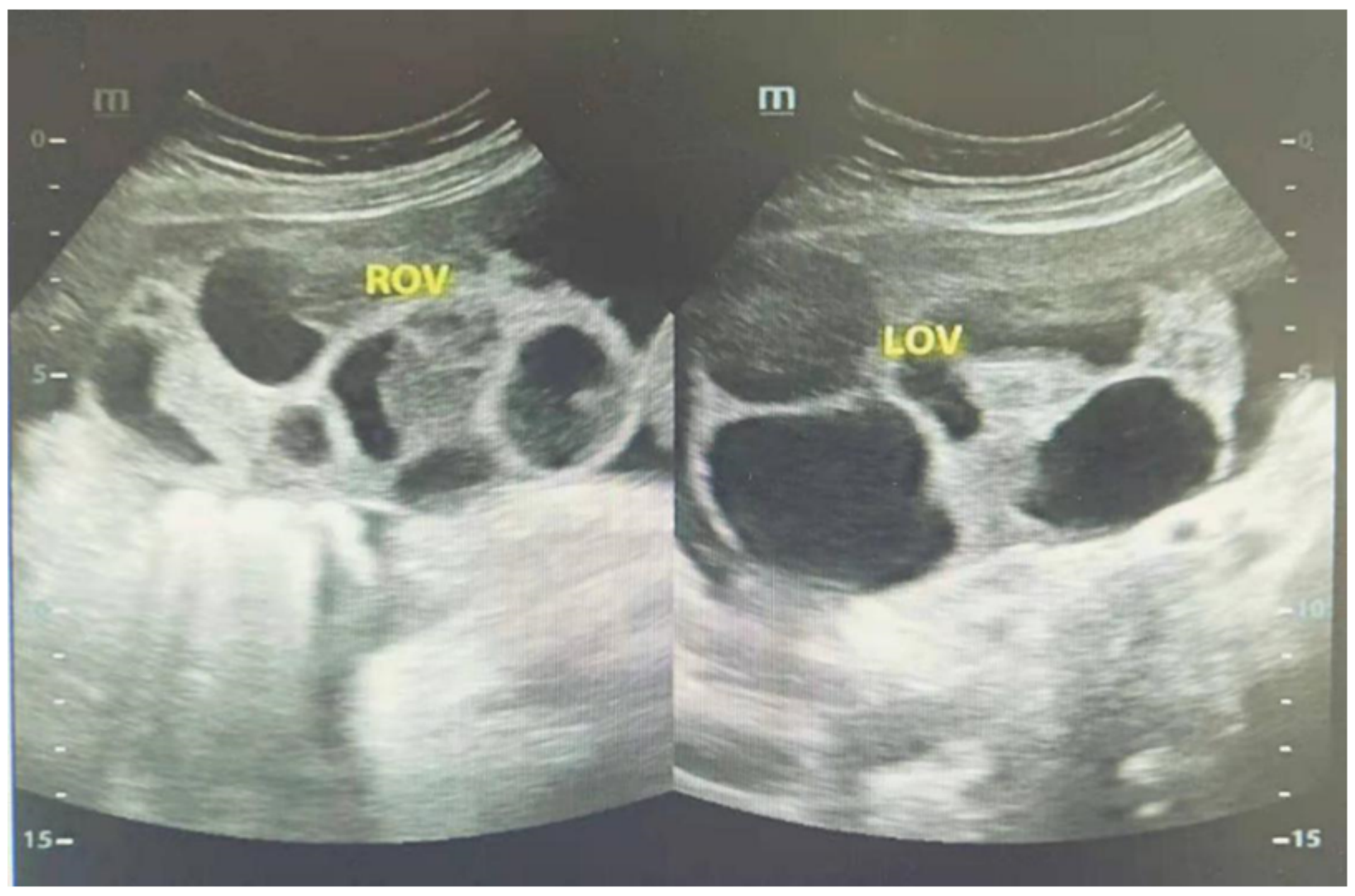

\section{Figure 1}

the results of vaginal type B utrasound monitoring on the 8th day after oocyte retrieval 